\title{
Comparison of Back-Leg Muscle Strength in Physically Active and Inactive Administrative Job Workers: A Cross-Sectional Study
}

\author{
Tirth Rambhia', Shwetanjali Bhagra \\ ${ }^{1}$ BPTh (Intern); ${ }^{2}$ Assistant Professor, Department of Musculoskeletal Health Sciences Physiotherapy; \\ Dr. VitthalraoVikhe Patil College of Physiotherapy, Ahmednagar, India.
}

Corresponding Author: Tirth Rambhia

\begin{abstract}
This study has been undertaken to assess the back-leg muscle strength in administrative job workers and then compare the readings/values of physically active population with physically inactive population of administrative staff, in Dr. Vithalrao Vikhe Patil Memorial hospital and medical college. The study used "IPAQ-sf Questionnaire" to estimate the level of physical activity and amount of sitting behaviour in hours throughout the day of the week and "Isometric back-leg-chest dynamometer" to assess the back and leg muscle strength of the 74 administrative staff, male (68.9\%) and female (31.1\%) involved in the study. The findings of the study indicated significant differences in the back-leg muscle strengths of both physically active and inactive population in both the male and female groups. On comparing the physically active population with physically inactive, in the male group inactive the results showed a significant difference in back muscle strength (0.0224) and leg muscle strength (0.0289) and in female group the leg strength $(0.0200)$ showed a higher significant difference than back strength (0.0003). This workplace delivered that the more the physical active of an individual irrespective of the age and genders the better the back-leg muscle strength and the more number of years a person worked in a sittingenvironment weaker the back-leg muscle strength.
\end{abstract}

Keywords: Physical activity, Physical inactivity, Dynamometry, Isometric Dynamometer, BLC dynamometer, Administrative workers.

\section{INTRODUCTION}

Rapid progress of civilization almost completely deprives of the opportunity to movement and physical effort. Physical activity is eliminated from the everyday life. "Human body was never created for a lifestyle involving continuously sitting tasks, it was created to move!". ${ }^{[1]}$ However, for a living, people sometimes have to compromise this fact and pursue certain types of occupation which demands long hours of sitting activity over movement. Adults spend at least one-third of the waking hours work is becoming more sedentary. ${ }^{[2]}$

In the modern world, the workforce throughout has undergone a lot of modifications and so the jobs that require employees to remain seated i.e., to remain less active and more sedentary for extended periods are continually increasing. [3] According to the official records published by "occupational requirements survey2017", among office and administrative occupations, by $65.6 \%$ of the work being spent as sitting, they are considered as sedentary jobs. Among legal occupations $78.1 \%$ of the workday goes in sitting position. On average, workers in computer and mathematical occupations spend $83.5 \%$ of the workday sitting. Business and financial operations workers also spend an average of 80.6 percent of the day sitting $[4,5]$. 
These occupations frequently expose employees to prolonged periods of sitting that has been identified to be a potentially significant occupational health hazard and a major concern in recent times ${ }^{[6]}$, since sitting for long duration of hours beyond a particular time period has increased prevalence of chronic diseases including coronary heart disease ${ }^{[7]}$, diabetes ${ }^{[8]}$, obesity ${ }^{[9]}$, and breast cancer ${ }^{[10]}$, as well as increased mortality from all causes [11] According to a study by Serxner et al. ${ }^{[12]}$ there was a link between behavioural health risk and absenteeism in sitting job workers. This was due mainly to the presence and prevalence of both metabolic and mental diseases associated with sedentary working conditions.

Risk of musculoskeletal disorders has also been linked to increased exposure to sitting at work ${ }^{[13]}$. Previous studies have demonstrated that there is a U-shaped relationship between LBP and PA ${ }^{[14,15]}$. These studies showed that sedentary lifestyle and strenuous levels of PA both are more associated with LBP than moderately intense PA ${ }^{[16-18]}$.

\section{What happens When You Sit?}

When your body assumes sitting posture, explains Cornell University, much of your weight is transferred to the pelvis, particularly to the ischial tuberosity. When you sit, muscles do most of the work against gravity, as long as you practice proper posture. In this position, the muscles deep in your abdomen, pelvis and back collectively known as the 9 core stability muscles (rectus abdominis, iliocostalis lumborum and multifidus muscles) - support your upright posture. However, if there is adaptation of the faulty posture due to prolonged sitting, these muscles supporting the spine become stiff and weak resulting in low back pain. The fascia though is tough being pliable it attains the shape of the faulty posture maintained throughout the day ${ }^{[1,19,20,21]}$.

Because sitting leaves your leg muscles at rest, the Department of Health and Human Services at Victoria, Australia, warns that prolonged sitting can lead to weakening of large leg and gluteal muscles. Extended periods of sitting also stress the hip flexors (iliopsoas muscle), causing them to shorten over time and leading to improper walking and irregular posture while standing which can be easily seen while standing. Additionally, the added pressure to the hamstrings can affect blood circulation, leading to muscle breakdown. [22] You also may notice that your hamstrings feel tight after a long day of sitting at your desk; this can cause them to pull on your lower back and create back pain. Along with all the focus on back pain, it has been ignored that prolonged sitting has proved to be one of the prime causes of "The dead butt syndrome" or so called in the textbooks "Lower cross syndrome" [23].

According to Cornell University, sitting puts about 40 to 90 percent more pressure on your back compared to standing. Those who perform office/desk work are sitting on average 8-12 hours/day during work days, and 7-9.5 hours/day on days off. These trends also have adverse effects such as weight gains, type-2diabetes, obesity, DVT and cardiovascular

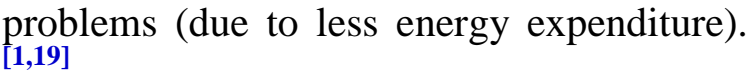

Prolonged sitting periods with poor posture and repetitive movements of the upper extremity, both of which have been linked as causes of neck and shoulder pain [24]. Studies have also shown that an individual having a job requiring sitting for a long period of time have a larger probability of facing neck/back pain due to stressful and static abnormal posture ${ }^{[25]}$.

Prolonged sitting is a topic of concern in many occupational groups such as office workers [26]. High rates of sedentary behaviours with low physical activity have been demonstrated in particular groups of office workers including managers, professionals, clerical and administrative workers ${ }^{[27]}$, public service workers ${ }^{[8]}$, and health company workers ${ }^{[28]}$. One reason for this might be the shift to the 'paperless office' and the 
growing prevalence of computerized work environments ${ }^{[1]}$.

Observational studies of Australian office workers have demonstrated that up to two-thirds of a working day, or half of an office-worker's waking hours are spent in sedentary postures ${ }^{[26,29]}$.

Because of specificity of work performed, all these desk workers are especially exposed to a risk of occurrence of such diseases ${ }^{[30]}$ and that raises a problem of constructing programmed, intentional physical activity for this group of employees.

Preventive medicine, often helpless to well-known civilization diseases and especially to new health risks, calls for appreciation of importance of health prevention and health promotion ${ }^{[31,33,30,32]}$. It is thus justified to quantitatively assess not only total but as well everyday - low, moderate and vigorous habitual physical activity that will allow for an unbiased and relative appraisal of importance of these independent variables in health promotion and will help in constructing appropriate programs of physical activity.

Physical activity (PA) is typically defined according to Caspersen et al. as: "any bodily movement produced by skeletal muscles that results in energy expenditure beyond resting expenditure ${ }^{[34]}$, usually over 1.6 metabolic equivalent. Physical inactivity is the absence of physical activity or exercise that fails to meet the standard physical activity for health ${ }^{[35]}$. Public health guidelines recommend regular $\mathrm{PA}$ to minimize the risk of chronic diseases $[34,36,37]$. It is commonly believed that nature of work of office employees does not require high physical efforts but there are still only suppositions about it since few data exist supporting that view.

Given that average working hours have generally increased over the past 32 years [38], with adults now spending an average of more than 8 hours of their weekday at work ${ }^{[39]}$, the workplace is a key setting in which to introduce strategies to reduce sitting time and break up periods of prolonged sitting to improve health and physical activity ${ }^{[40,41]}$.

A typical official job which requires a person to work at desk sitting for 8 hours a day, 5 hours a week is enough to cause ill effects of a bad posture due to sitting. ${ }^{[1]}$ Thus, the study tries to create awareness and give a feedback that- "relieving the body from ill effects of long-term sitting work demands is more important than punishing oneself to satisfy one' mind for monetary needs".

\section{MATERIALS AND METHODOLOGY}

2.1 Study Design - Observational, Crosssectional study

2.2 Study Set Up- In Vikhe Patil Memorial Hospital and medical College, Ahmednagar city

\subsection{Sample Size - 74}

\subsection{Sample Techniques - Purposive technique}

2.5 Study Material- Back-leg-chest dynamometer, Laptop, weighing machine, a measuring tape, a notebook and a pen.

2.6 Inclusion Criteria: Healthy administrative job workers- both gender, age 24-55 years, with working hours of minimum 8-hours/day.

2.7 Exclusion Criteria: Administrative workers with any sports injury to limbs, any underlying neuromuscular or musculoskeletal disorder, any cardiovascular, respiratory diseases and Subjects suffering from any psychiatric disorder affecting their psychomotor abilities.

\subsection{Outcome Measures: \\ INTERNATIONAL PHYSICAL ACTIVITY QUESTIONNAIRE: $[20,21,22]$}

The regular physical activity of the patients was assessed and recorded with 
the help of a questionnaire, through face to-face interview using, IPAQ-short form (IPAQ Research Committee 2005). It concentrates on three specific activities which are walking activity, moderate intensity activities and vigorous-intensity activities. The question on sitting activity indicates the time period utilized in sedentary activities but it is not included in the calculation of the total physical activity score. Scoring method of IPAQ is kind of different and is expressed in terms of medical equivalent (MET). The IPAQ can classify an individual's activity as "Health-Enhancing Physical Activity (HEPA)" when the total score is 3000 MET-minutes (50 MET-hours)/week or more, "Active" when the total score is 600 MET-minutes (10 MET-hours) or more, and "Inactive" when the total score is below 600 MET-minutes (10 MET-hours). In this study, "HEPA" and "Active" were considered as participate, and "Inactive" was considered as nonparticipate ${ }^{[22]}$.

\section{BACK-LEG MUSCLE STRENGTH MEASUREMENT: ${ }^{[23,24]}$}

Back leg muscle strength is measured in the study by an: "Isometric Back-LegChest Dynamometer" with an analogue dial is an instrument used to measure muscular strength of the back muscles, leg muscles and chest muscles. The measurement base provides secure footing. Chain length is adjusted to accommodate for height differences or to vary the point of force application. Maximum reading remains until the unit is reset. The strength reading can be viewed as pounds or kilograms. The dynamometer can be used to measure various muscles all over the body however, for this research the dynamometer was used to measure only back muscles and leg muscles strength, both having different procedures to be measured.

\subsection{Procedure:}

Institution ethical committee approval was obtained before commencing the study. Healthy administrative workers were selected based on the inclusion and exclusion criteria. The subjects were explained in detail about the procedure, benefits and the need of the study and then the informed consent was obtained, in the language best understood by them, before involving them in the study. Basic demographic data and anthropometric measurements like: name, age, gender, dominance, weight, height, BMI; along with duration of occupational sitting hours and interval hours were documented on the data sheets. Their physical activity and sitting time period were calculated with help of "IPAQ-sf Questionnaire" and the back and leg muscle strength was measured with the help of an objective source, i.e., "Isometric back-leg-chest dynamometer". The administrative staff were then segregated into 2 groups depending upon their physical activity scores i.e., physically active (PA) population and physically inactive (PinA) population, and then the male PA population back-leg muscle strength were compared with male PinA and similarly the female PA population back-leg muscle strength was compared with female PinA

The procedure for measuring the back-leg muscle strength with an isometric back-leg-chest dynamometer is ${ }^{[49]}$.

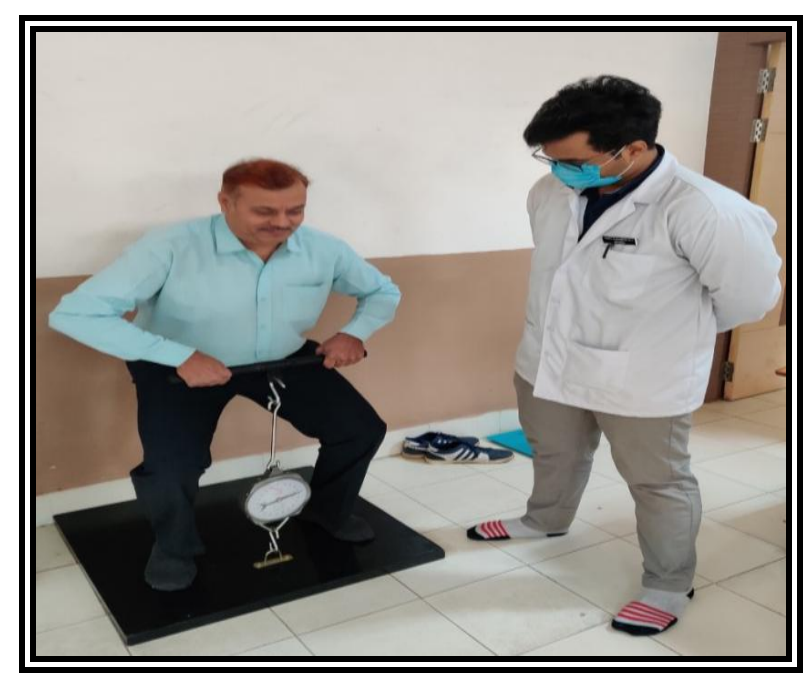

Figure 1: Leg muscle strength testing with an isometric backleg-chest dynamometer. 
Tirth Rambhia et.al. Comparison of back-leg muscle strength in physically active and inactive administrative job workers: a cross-sectional study.

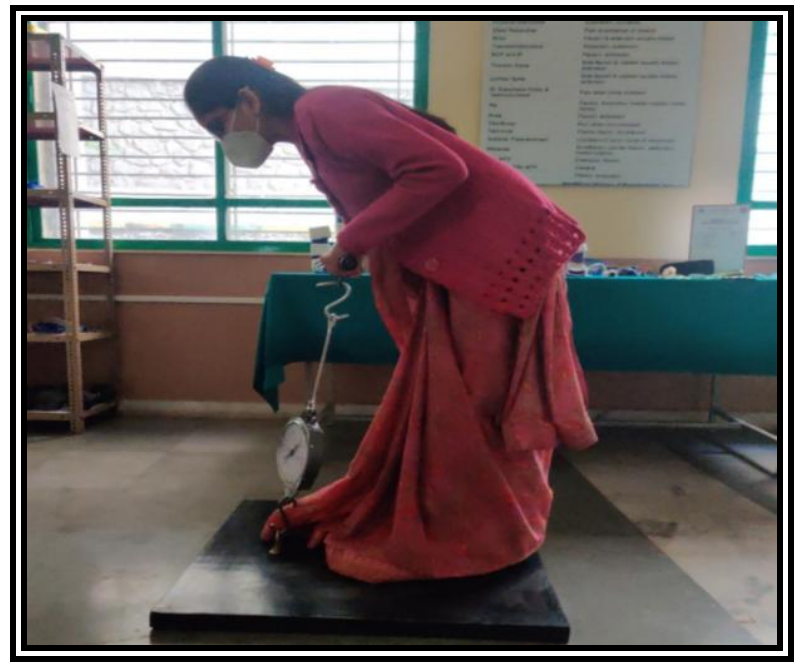

Figure 2: Back muscle strength testing by an isometric back-leg-chest dynamometer

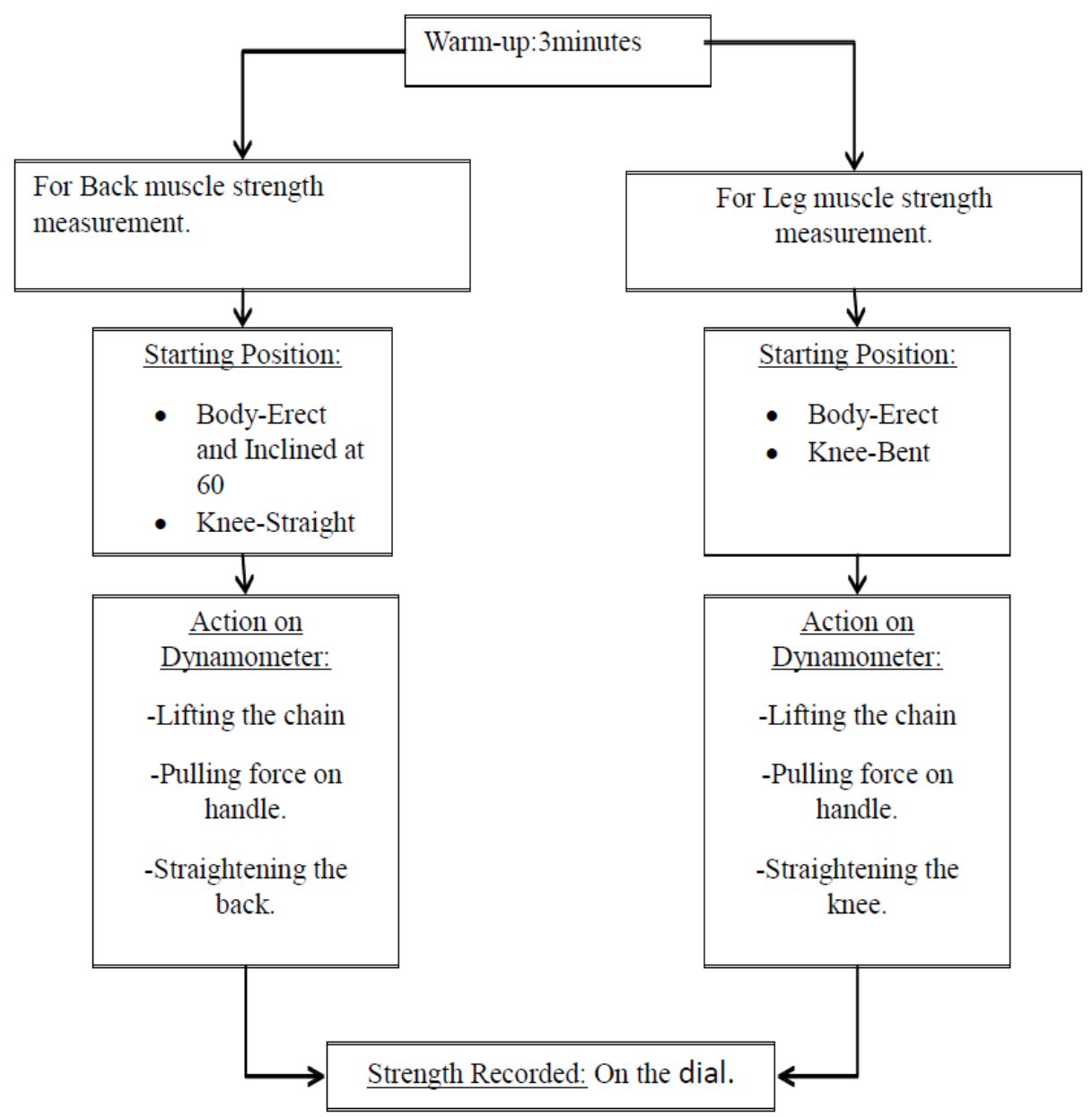

\section{Statistical Methods:}

Unpaired t-test was used to compare back-leg muscle strength of physically active and inactive populations of both male and female administrative workers.

\section{RESULTS}

A total of 74 participants were examined, 51 males and 23 females. Descriptive statistics for the baseline characteristics of the participants by gender are presented in table 1 . The average age for male and female administrative workers included in the study was $36.3 \pm 8.5$. The 
Tirth Rambhia et.al. Comparison of back-leg muscle strength in physically active and inactive administrative job workers: a cross-sectional study.

mean height and weight of the administrative workers was $164.42 \pm 9$ and $164.42 \pm 9$ respectively. The administrative staff were also interviewed for the amount of time they spent sitting performing their occupational tasks and on an average the hours were $7.3 \pm 0.7$. The graph 1 below represents the results depicted in the table.

Table 1: Baseline characteristics of the administrative workers.

\begin{tabular}{|l|l|l|l|}
\hline & $\begin{array}{l}\text { Total } \\
\text { Mean }(\text { SD) }\end{array}$ & $\begin{array}{l}\text { Male } \\
\text { Mean } \\
\text { (SD) }\end{array}$ & $\begin{array}{l}\text { Female } \\
\text { Mean } \\
\text { (SD) }\end{array}$ \\
\hline Age & $36.3 \pm 8.5$ & $36.66 \pm 8.6$ & $35.48 \pm 8.5$ \\
\hline Height & $164.42 \pm 9$ & $168.07 \pm 5.7$ & $156.3 \pm 11$ \\
\hline Weight & $164.42 \pm 9$ & $71.85 \pm 11.8$ & $59.68 \pm 6.8$ \\
\hline BMI time & $24.9 \pm 3.8$ & $25.1 \pm 3.5$ & $24.55 \pm 4.2$ \\
\hline $\begin{array}{l}\text { Occupation } \\
\text { period }\end{array}$ & $10.38 \pm 7.4$ & $10.97 \pm 8$ & $9 \pm 5.5$ \\
\hline $\begin{array}{l}\text { Occupational } \\
\text { Sitting duration }\end{array}$ & $7.3 \pm 0.7$ & $7.26 \pm 0.8$ & $7.39 \pm 0.5$ \\
\hline
\end{tabular}

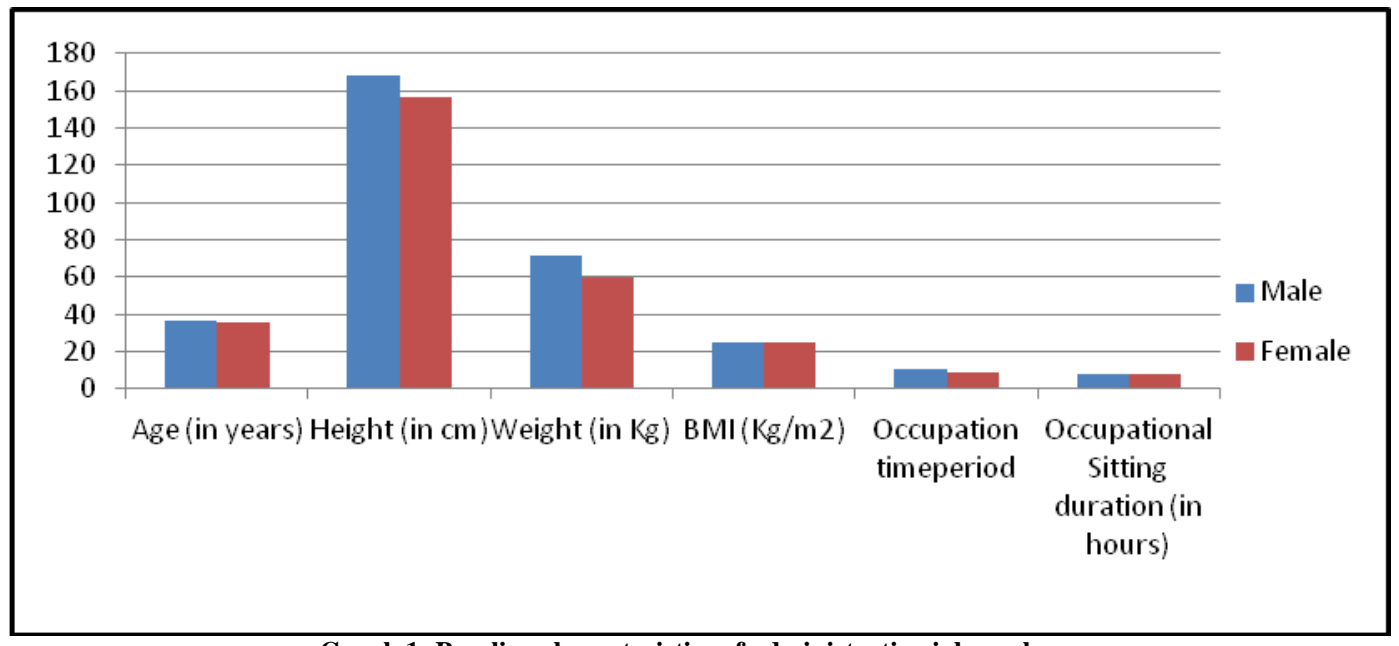

Graph 1: Baseline characteristics of administrative job workers.

The male and female administrative workers were assessed for their physical activity with the help of "IPAQ: International Physical Activity Questionnaire-short form". In the male group, the physically active population had a mean score of $1804.36 \pm 2027$ and the physically inactive population had a score of $202 \pm 221$. In the female group, the physically active population had a mean score of $1652.8 \pm 1472.88$ and the physically inactive population had a score of $215.92 \pm$ 204.5 .
Table 2: Physical activity means scores of both active and inactive populations of administrative workers.

\begin{tabular}{|l|l|l|} 
inactive populations of administrative workers. \\
\hline & $\begin{array}{l}\text { Active population } \\
\text { Mean (SD) }\end{array}$ & $\begin{array}{l}\text { Inactive population } \\
\text { Mean (SD) }\end{array}$ \\
\hline Male & $1804.36 \pm 2027$ & $202 \pm 221$ \\
\hline Female & $1652.8 \pm 1472.88$ & $215.92 \pm 204.5$ \\
\hline Total & $1737.24 \pm 1771.038$ & $201.85 \pm 212.97$ \\
\hline
\end{tabular}

The overall back muscles and leg muscles strength in two different populations, physically active and inactive population, of administrative job workers were compared. The research selected an objective measure, "Isometric Back-LegChest Dynamometer" to assess the backleg muscles strength in every individual participant. The comparative statistics are given in Table 3.

Table 3. Comparison of physical activity score, back-leg muscle strength in active and inactive population of administrative job workers.

\begin{tabular}{|l|l|l|l|l|}
\hline & Back-leg muscle strength & Active population Mean (SD) & Inactive population Mean(SD) & p-value \\
\hline Male & Back muscle strength score Mean(SD) & $80.78 \pm 16.74$ & $68.17 \pm 16.95$ & 0.0224 \\
\hline & Leg muscle strength score Mean(SD) & $86.07 \pm 19.87$ & $73.02 \pm 17.66$ & 0.0289 \\
\hline Female & Back muscle strength score Mean(SD) & $63.18 \pm 6.3$ & $49.83 \pm 8.2$ & 0.0003 \\
\hline & Leg muscle strength score Mean(SD) & $61.18 \pm 8.8$ & $52.42 \pm 7.9$ & 0.0200 \\
\hline
\end{tabular}


Tirth Rambhia et.al. Comparison of back-leg muscle strength in physically active and inactive administrative job workers: a cross-sectional study.

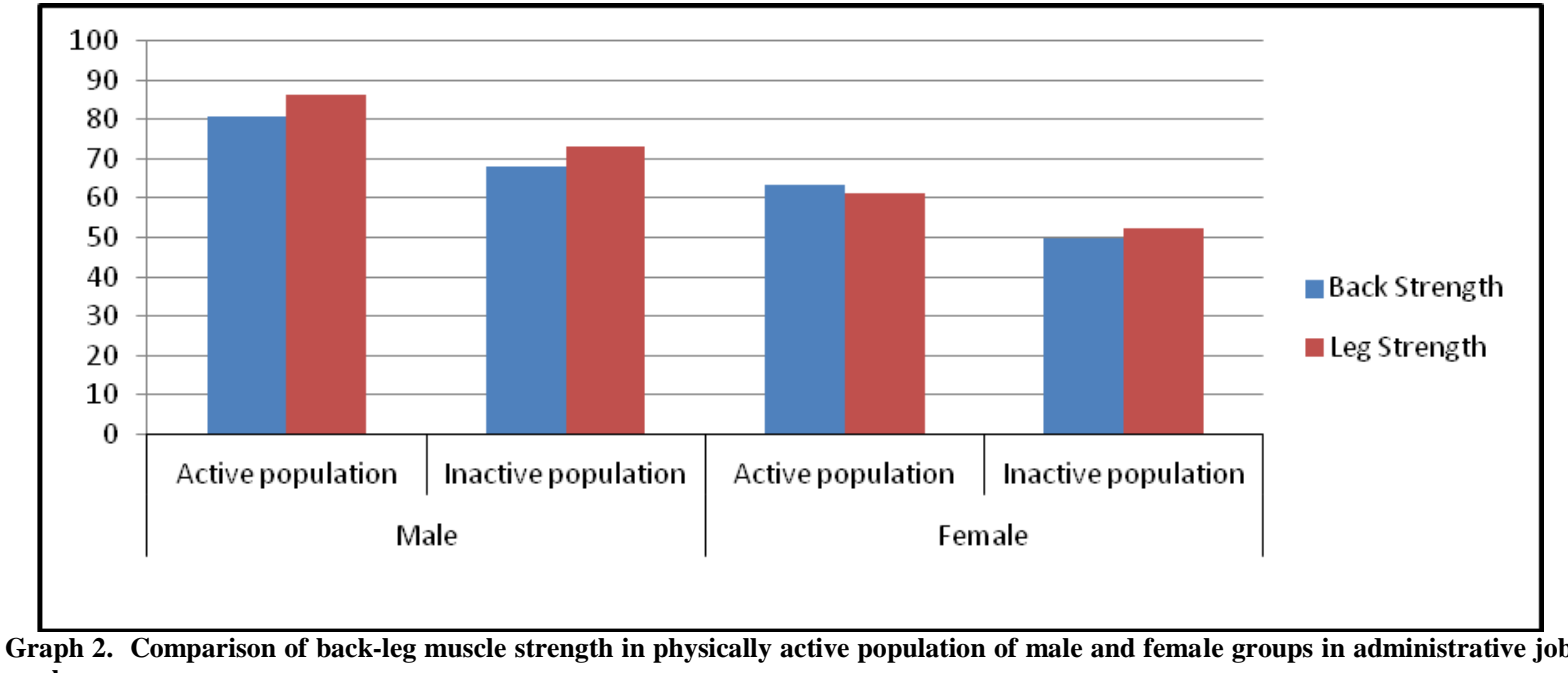
workers.

The back-leg strength of the two populations (Physically active and inactive) of male and female group when compared with each other showed significant difference for both back muscle strength (0.0004) and leg muscle strength (0.0033). In the male group, when the physically active participants were compared with physically inactive the results showed a significant difference in back muscle strength $(\mathrm{p}=0.0224)$ and leg muscle strength $(p=0.0289)$. In the female group, when the physically active and inactive populations were compared the leg strength $(p=0.02)$ showed a significant difference than back strength $(\mathrm{p}=0.0003)$.

\section{DISCUSSION}

There is change in the nature of modern occupational structure and physical functional demands making the jobs more and more sedentary based leading to increase in chronic sedentary diseases affecting working adults. Thereby, regular assessment and measurement of physical activity and basic strength testing of muscles that are most affected by sitting at the workplace has become more crucial in maintaining the productivity at the worksite and focusing on an individual's long-term health. The study was conducted since there is a lack of literature concerning back-leg muscle strength altering with the level of physical activity in administrative and so the study was conducted. A study conducted in the USA on the administrative worker to assess the sedentary behaviour of the college employees was observed to have about 618 minutes (10.3 hours) of sitting activity throughout a working day. The results indicated that administrative workers $(73.2 \pm 17.7 \%)$ spent more of their working day sedentary than faculty members $(58.5 \pm 19.6 \%, \mathrm{p}<0.05)^{[44]}$. Similarly, in this study as well all the administrative workers were evaluated for their sitting time with "The IPAQ-sf Questionnaire" and an average of the total hours spent by them sitting during their non-working hours and working hours was observed to be 10.49 \pm 1.5 hours/day/week of the 24 hours in a day. An administrative worker in a medical college sits about 8 hours on an average for occupational needs, which according to the Indian occupational demands is from morning 9 am to evening $5 \mathrm{pm}$, with an interval of an hour. However, the sitting duration of any administrative workers is not affected much by the interval since in the interval too they spend their time sitting on a chair.

It was observed in twenty studies (representing 11 data sets), all from developed world economies when reviewed and underwent a data analysis using a range of analytical techniques (e.g., accelerometer counts or pattern recognition algorithms) that: "Blue-collar" workers (Sedentary group of workers) were more sedentary and less active during nonwork compared with 
work time (e.g., sitting 5.7 vs $3.2 \mathrm{~h} / \mathrm{d}$; moderate to vigorous PA 0.5 vs $0.7 \mathrm{~h} / \mathrm{d}){ }^{[45]}$. These findings provided a firm background to check up on another set of the sedentary working group i.e., the administrative department of a medical college.

This study consisted of a total of 74 administrative job workers, 51 males, and 23 females, from medical staff in Dr. Vitthalrao Vikhe Patil Foundation, from which 2 male participants dropped out due to the presence of mechanical low back pain during the time. Thereby, resulting in a study sample of 72 participants. About $66.21 \%$ of the population was physically inactive and $33.78 \%$ were physically active.

The above-mentioned sitting behaviour of nearly 10 hours/day/week depicts administrative workers performed the least activity throughout a day. Therefore, providing a platform to identify the nature of physical activity a medical college administrative staff presents with. In a particular study conducted in the city of Milagro, Ecuador Graciela Mercedes Alvarez et al. used the IPAQ-sf Questionnaire consisting of 7 questions to identify the level of sedentary behaviour and physical activity of the administrative public sector workers. Similarly, this study too used the same IPAQ-sf Questionnaire to identify the sitting behaviour and physical activity of the administrative medical college workers ${ }^{[46]}$.

Furthermore, upon administering "The IPAQ-sf Questionnaire" on the medical administrative workers based on MET scores, they were segregated into two groups: physically active population $(\geq 600$ MET-minute/week) and physically inactive population (<600 MET-minute/week) ${ }^{[47]}$. The mean physical activity score of the total physically active population of administrative job workers was found to be $1737.24 \pm 1771.038$, which is quite higher when compared with that of the physically inactive population $201.85 \pm 212.97$. The physical activity of the total inactive population stands to be higher than people lying in bed. On average a Physically active male depicted an activity score of $1804.36 \pm$ 2027 and an inactive male depicted an activity score of $202 \pm 221$. On a similar line in the female group, the physically active population scored $1652.8 \pm 1472.88$, and the physically inactive score only $215.92 \pm 204.5$.

The nature of their work is such that it provides the administrative workers with fewer opportunities to undertake physical activity and a closed office environment is what may affect muscle atrophy and reduce the MVC (maximal voluntary contraction) [48], which in this study is taken account for by assessing the back and leg muscle strength with the help of an "Isometric Back-Leg-Chest Dynamometer".

A study conducted by Shyamal Koley et al. used a back-leg-chest isometric dynamometer to correlate back strength and leg strength among Indian Inter-university cricketers ${ }^{[49]}$. In this study, a similar isometric back-leg-chest dynamometer was used to compare the back strength and leg strength of physically active individuals with that of physically inactive individuals, from all the 72 participants.

When the physically active population $(n=14)$ was compared with the physically inactive population $(n=37)$, in males: there was a significant difference for both back strength $(\mathrm{p}=0.0224)$ and leg strength $(\mathrm{p}=0.0289)$.

When the physically active population $(\mathrm{n}=11)$ was compared with the physically inactive population $(n=12)$, in females too: there was a significant difference for both back strength $(\mathrm{p}=0.0003)$ and leg strength $(\mathrm{p}=0.02)$.

Somewhat similar results of physical inactivity (moderate to vigorous PA $0.5 \mathrm{v} / \mathrm{s}$ $0.7 \mathrm{~h} / \mathrm{d})$ and sitting hours $(5.7 \mathrm{v} / \mathrm{s} 3.2 \mathrm{~h} / \mathrm{d})$ in sedentary workers and so-called "Bluecollar" workers were seen through a systemic review study considering about 20 studies all from developed countries ${ }^{[45]}$.

In the present study, more insight about the specific physical activity has been provided by focusing on the back strength and leg strength of the administrative job 
workers which was never compared in such a sedentary behaviour population before.

In males $(\mathrm{n}=51)$, the physically active population was 14 and the inactive population was 37 . Apart from there being a significant difference in the values of the physically active and inactive population, the mean leg muscle strength scores $(86.07 \pm 19.87)$ of the physically active population were seen to be the highest of all followed by the mean back muscle strength scores $(80.78 \pm 16.74)$.

In females $(n=23)$, the mean leg muscle strength differed in physically active $(61.18 \pm 8.8)$ and inactive population (52.42 \pm 7.9$)$ and back muscle strength inactive $(63.18 \pm 6.3)$ and inactive populations (49.83 \pm 8.2$)$ too differed.

However, the gender differences in maximal strength are minimal since they are mainly dependent on differences in the size of muscle fibers, with a cross-sectional muscle fiber area in women being about $75 \%$ of that in men ${ }^{[50]}$, the number of fibers of a muscle being about the same in both genders. Thus, no strength difference is found between women and men when strength is considered concerning the crosssectional area of the tested muscle ${ }^{[51]}$.

It was observed during the study that when the participants were interviewed regarding the recreational activities they involved in their daily routine, the physically active population mentioned them being either of the following: yoga, gym, cycling, and walking, taking into account their surroundings environment.

These specific physically healthy administrative workers were observed to have good leg and back muscular strength. This is not surprising because numerous previous studies are backing up the results. Of all the recreational activities Yoga, walking and cycling were observed to be among the common practices of their daily routine since these activities require minimal equipment or none. Also, regular yoga practice is observed to be widely practiced moderate physical activity just as effective as high physical activities such as stretching-strengthening exercises in improving functional fitness ${ }^{[52]}$.

Out of 74 administrative workers, it was observed that $5.4 \%$ had high physical activity, $24.32 \%$ had moderate physical activity and $70.27 \%$ had low physical activity.

Some administrative workers who were in the $24.32 \%$ group of moderate physical activity were also involved in certain farming activities. However, others, the ones' who were categorized as physically inactive were the ones' who after their 8 hours of occupational sitting would either prefer to sit at home, talking to family and friends, for longer hours or merely lie down watching television and taking rest. Little did they know they were exposing themselves to the prolonged harmful effects of sitting causing low back pain and various other musculoskeletal disorders. ${ }^{[\mathbf{5 3}, \mathbf{5 4 , 5 5 , 5 6}]}$

The reduction of physical activity has been known to induce muscle atrophy ${ }^{[57,58]}$, which results from atrophy of type II fibers recruited during intensive efforts ${ }^{[59]}$. The rate of atrophy is not uniform in all muscles, and for the lower limbs, it can be $2-12 \%$ after 5 weeks of bed rest ${ }^{[59]}$. In many muscles, but not in all, atrophy can be reduced by resistance training alone and by resistance combined with vibration stimulation (during 60-day immobilization in bed) ${ }^{[59]}$. And so, the sedentary population needs to be given awareness about not being too late to realize the facts and start with even certain amounts of physical activity be it a 20-minute small walk in the park twice a day.

Nevertheless, our study reveals the highest back-leg strength values in the physically active population of administrative workers, which may indicate that even the relatively low physical activity of active administrative workers (moderate activities $3 \times 1$ hour/week) was sufficient to maintain or increase muscle strength in the subject.

The findings of the following study carry immense practical application in Jobsectors helping both the job workers as well 
as job providers. The study spreads awareness about why an individual's selection of a job/occupation, work premise, and the healthy habits of daily living are of so much importance. Also, it is helpful to a company to decide upon its health policies while providing a job offer to an acclaimed professional.

All the community physical therapists working in industrial sectors as a health guide out there will be able to make the company owners, and health policy decision-makers understand the importance of workstation exercises and providing individuals with proper ergonomic conditions to work with intermediate regular breaks for preventing Musculoskeletal problems along with other health problems (Predisposition to DM, BP, obesity, etc.).

\section{CONCLUSION}

The main finding of this study is that when physically active and inactive populations were compared with each other for back and leg muscle strengths both the genders (male and female) showed a significant difference.

Both the back and leg muscle strength are equally important in administrative job workers as in any other sedentary or desk job workers. The data from this clearly showed that even a small amount of physical activity in an administrative worker showed a significant difference in his/her back-leg muscle strength, thereby reducing their chances of getting into a vicious cycle of Musculoskeletal or any other health problems.

In the case of the desk-job workers, a moderate level of daily physical activity, and preventing body weight and fat gain should be recommended for prevention and management of low back pain. Increases in exercise training enhance skeletal muscle mass and decrease musculoskeletal pain ${ }^{[61]}$.

Because of this, the desk-job workers should perform the levels of physical activity recommended by the World Health Organization, which is at least
$150 \mathrm{~min}$ of moderate-intensity aerobic physical activity throughout the week or at least $75 \mathrm{~min}$ of vigorous-intensity aerobic physical activity throughout the week, or an equivalent combination of moderate and vigorous-intensity activity ${ }^{[61]}$.

In addition, the male desk workers should take up vigorous activities gradually over some time only if they are going to continue the same or better avoid engaging in the same. Similarly, the female desk-job workers should avoid vigorous physical activity which may cause back muscle strains or ligament strains, such as: lifting heavy objects, twisting or sudden

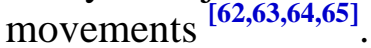

\section{Acknowledgement: None}

Conflict of Interest: None

\section{Source of Funding: None}

\section{Ethical Approval: Approved}

\section{REFERENCES}

1. Pollock AS, Durward BR, Rowe PJ, et al. What is balance? ClinRehabil, 2000, 14: 402-406.

2. Quitschal RM, Fukunaga, et al. Evaluation of postural control in unilateral vestibular hypofunction. 2014; 80(4):339-45.

3. Katz J. M. L., Burkard R., Hood L. J. Handbook of Clinical Audiology. Lippincott Williams \& Wilkins; 2009

4. Wade DT, Hewer RL: Functional abilities after stroke: measurement, natural history and prognosis. J NeurolNeurosurg Psychiatry, 1987, 50: 177-182.

5. Petró B, Papachatzopoulou A, Kiss RM (2017) Devices and tasks involved in the objective assessment of standing dynamic balancing - A systematic literature review. PLoS ONE 12(9): e0185188.

6. Verbecque E, Lobo Da Costa PH, Vereeck L, Hallemans A. Psychometric properties of functional balance tests in children: A literature review. Dev Med Child Neurol. 2015;57: 521-529.

7. Marco GDISShislieri, Laura Gastaldi, et al. Wearable Inertial Sensors to Assess 
Tirth Rambhia et.al. Comparison of back-leg muscle strength in physically active and inactive administrative job workers: a cross-sectional study.

Standing Balance: A Systematic Review Sept 2019; 19(19): 4075

8. Yu-Liang Hsu, Pau-Choo (Julia) Chung et al. Gait and Balance Analysis for Patients With Alzheimer's Disease Using an InertialSensor-Based Wearable Instrument. IEEE journal of biomedical and health informatics.november2014;18(6):1822-1830

9. K.J. Sheehan, B.R. Greene et.al. Early identification of declining balance in higher functioning older adults:an inertial sensor based method. Gait and balance; 39(2014):1034-1039.

10. SelineWüest, Fabien Massé et.al Reliability and validity of the inertial sensor-based Timed "Up and Go" test in individuals affected by stroke.JRRD. 2016;53(5): 599610

11. Kyoung Jae Kim 1,2, Yoav Gimmo et.al Using Inertial Sensors to Quantify Postural Sway and Gait Performance during the Tandem Walking Test. MDPI. Feb 2019;19:751

12. Computerized Dynamic Posturography (CDP) 2018. Medical Coverage Policy

13. Martin Vališ, Jakub Dršata et.al Computerised static posturography in neurology. Central European Journal of Medicine.2012; 7(3):317-322.

14. F. Donáa,b, *, C.C. Aquino et.al Changes in postural control in patients with Parkinson's disease: a posturographic study. 2016; 102(3), 272-279.

15. Steven P. Broglio, Jacob Sosnoff et.al A Comparison of Balance Performance: Computerized Dynamic Posturography and a Random Motion Platform. Arch Phys Med Rehabil 2009; 90: 145-50.

16. Martha R. Hinman. Factors Affecting Reliability of the Biodex Balance System: A summary of Four Studies. J Sport Rehabil. 200;9:240-252.

17. Furqan Ahmed Siddiqi 1, Tahir Masood .Training on Biodex balance system improves balance and mobility in the elderly. J Pak Med Assoc. November 2018;68(11):1655-1659

18. Ibrahim AA1*, Mohamed AMR et.al The relevance of balance assessment to detect balance deficits in obese subjects: A cross sectional study. Biol Med Case Rep.2018; 2(1):15-20.

19. Bina Eftekhar-Sadat, Roghayyeh Azizi, Akbar Aliasgharzadeh. Effect of balance training with Biodex Stability System on balance in diabetic neuropathy. Ther Adv Endocrinol Metab 2015; 6(5):233 -240.

20. Narcis Gusi1, Jose Carmelo Adsua et.al Balance training reduces fear of falling and improves dynamic balance and isometric strength in institutionalised older people: a randomised trial Journal of Physiotherapy.2012;58: 97-104.

21. Chia-Hsuan Lee and Tien-Lung Sun Evaluation of postural stability based on a force plate and inertial sensor during static balance measurements. Lee and Sun Journal of Physiological Anthropology. 2018;37:27

22. Kathryn A. Chung, Brenna M. Lobb, et al. Objective Measurement of Dyskinesia in Parkinson Disease using a Force Plate. NIH Public Access-Mov Disord .2010 April 15; 25(5): 602-608

23. Bickley C, Linton J, Sullivan E, Mitchell K, Slota G, et al. Comparison of Simultaneous Static Standing Balance Data on a Pressure Mat and Force Plate in Typical Children and in Children with Cerebral Palsy. Gait and amp; Posture; 2018

24. Harro, Cathy C. PT, DPT; Garascia, Chelsea PT, DPT. Reliability and Validity of Computerized Force Platform Measures of Balance Function in Healthy Older Adults Journal of Geriatric Physical Therapy: July/September 2019; 42(3):57-66

25. Brenton-Rule et al. Reliability of the TekScanMatScan system for the measurement of postural instability in older people with rheumatoid arthritis. Journal of Foot and Ankle Research 2012, 5:21

26. Goetschius J, Feger MA, Hertel J, et al. Validating Center of Pressure Balance Measurements Using the MatScan ${ }^{\circledR}$ Pressure Mat. Journal of Sport Rehabilitation. 2017.

27. Yang Yang, Fang Pu, et al Reliability and Validity of Kinect RGB-D Sensor for Assessing Standing Balance. Ieee Sensors Journal. May 2014;14(5), 1633-1668.

28. Pablo Rodrigo DIAZ-MONTERROSAS, Ruben POSADA-GOMEZ et al A Brief Review on the Validity and Reliability of Microsoft Kinect Sensors for Functional Assessment Applications. Advances in Electrical and Computer Engineering. 2018;18(1):132-136.

29. Jingbo Zhao, Frank E. Bunn et al Gait Assessment using the Kinect RGB-D Sensor. Ieee Sensors Journal. 2015;14(5), 6679-6683. 
Tirth Rambhia et.al. Comparison of back-leg muscle strength in physically active and inactive administrative job workers: a cross-sectional study.

30. Clark et al. Instrumenting gait assessment using the Kinect in people living with stroke:reliability and association with balance tests. Journal of NeuroEngineering and Rehabilitation .2015;12:15.

31. Helen Cohen et. al. Study of the Clinical Test of Sensory Interaction and Balance. Physical Therapy.June 1993; 73(6):346-351.

32. Khattar VS, Hathiram BT. The clinical test for sensory integration of balance. Int Journal of Otorhinolaryngol Clin. 2012; 4(1): 41-45

33. T. JoseleySunderraj Pandian et. al. Clinical test of sensory interaction in balance (CTSIB): Concurrent validity study in healthy Indian children. Journal of Pediatric Neurology .2011;(9): 311-318

34. YonesLotfi et. al. Modified clinical test of sensory interaction on balance test use for assessing effectiveness of Epley maneuver in benign paroxysmal positional vertigo patients rehabilitation. Aud Vest Res (2018);27(1):12-18.

35. W.H.O. Global Recommendations On Physical Activity For Health. WHO PRESS; 2010.

36. U.S. Department of Health and Human Services. Physical activity and health: A report of the Surgeon General. Washington: DIANE Publishing; 1996.

37. U.S. Department of Health and Human Services. 2008 physical activity guidelines for Americans. Be active, healthy, and happy. Washington: USDHHS; 2008.

38. Schmidt H, Barrett D, W. Ortmann L, Dawson A, et al., Chronic Disease Prevention and Health Promotion. 2016 Apr 13. In Public Health Ethics: Cases Spanning the Globe [Internet]. Cham (CH): Springer; 2016. Chapter 5. Available from: https://www.ncbi.nlm.nih.gov/books/NBK4 35779/ doi: 10.1007/978-3-319-23847-0_5

39. Australian Bureau of Statistics: Australian Labour Market Statistics. Catalogue number 6105.0. 2011, Sydney: Australian Bureau of Statistics

40. Bureau of Labor Statistics: American Time Use Survey, 2009. 2010, Washington, DC: Bureau of Labor Statistics

41. Alkhajah TA, Reeves MM, Eakin EG, Winkler EA, et al: Sit-stand workstations: a pilot intervention to reduce office sitting time. Am J Prev Med. 2012, 43: 298-303. 10.1016/j.amepre.2012.05.027.
42. National Preventative Health Taskforce: Australia: The Healthiest Country by 2020: National Preventative Health Strategy: The Roadmap for Action. 2009, Canberra: Commonwealth of Australia

43. Sarah K. Keadle, David E. Conroy, Matthew P. Buman, David W. Dunstan, Charles E. Matthews. Targeting Reductions in Sitting Time to Increase Physical Activity and Improve Health.Med Sci Sports Exerc. Author manuscript; available in PMC 2018 Aug 1.Published in final edited form as: Med Sci Sports Exerc. 2017 Aug; 49(8): 1572-1582.

doi: 10.1249/MSS.0000000000001257 PMCID:PMC5511092

44. Samuel Headley et al, Subjective and objective assement of sedentary behavioramaong college employees, BMC Public Health (2018) 18:768, https://www.researchgate.net/publication/32 5856977_Subjective_and_objective_assess ment_of_sedentary_behavior_among_colleg e_employees.

45. Graciela, Álvarez-Condo1; Mariana, Guadalupe-Vargas2; Herminia, MoralesMurillo3; Junes, Robles-Amaya. Sedentary lifestyle and physical activity in administrative public sector workers. Vol. 9, No 21, Diciembre 2016, pp. 116 - 124 ISSN 1390-4272 Impreso ISSN 2528-7737 Electrónico.

46. WHO. [accessed Feb-10 2015];Global recommendations on physical activity for health. $2010 \mathrm{http}: / /$ whqlibdoc.who.int/public ations/2010/9789241599979_eng.pdf

47. Gilson ND, Hall C, Holtermann A, van der Beek AJ, Huysmans MA, Mathiassen SE, Straker L. Sedentary and Physical Activity Behavior in "Blue-Collar" Workers: A Systematic Review of Accelerometer Studies. J Phys Act Health. 2019 Nov 1;16(11):1060-1069. doi: 10.1123/jpah.2018-0607. Epub 2019 Aug 29. PMID: 31469366.

48. Mariusz Naczk, et al. Muscle Strength In Physically Active And Inactive Prisoners. Studies in physical culture and tourism Vol. 18, No. 3, 2011.

49. Shyamal Koley, Aseem Khajuria, Sheri Melton. The Correlation Between Back Strength And Leg Strength Among Indian Inter-University Male Cricketers, FACTA UNIVERSITATIS Series: Physical 
Tirth Rambhia et.al. Comparison of back-leg muscle strength in physically active and inactive administrative job workers: a cross-sectional study.

Education and Sport Vol. 8, No 2, 2010, pp. 125-132,UDC 796.358:572.087

50. Costill DL, Daniels J, Evans W, et al. Skeletal muscle enzymes and fiber composition in male and female track athletes. J ApplPhysiol1976;40:149-54.

51. Schantz P, Randall-Fox E, Hutchinson W, et al. Muscle fibre type distribution, muscle cross-sectional area and maximal voluntary strength in humans. Acta PhysiolScand. 1983;117:219-26]

52. Gothe NP, McAuley E. Yoga Is as Good as Stretching-Strengthening Exercises in Improving Functional Fitness Outcomes: Results From a Randomized Controlled Trial. J GerontolABiol Sci Med Sci. 2016 Mar;71(3):406-11. doi: 10.1093/gerona/glv127. Epub 2015 Aug 22. PMID: 26297940; PMCID: PMC5864160.

53. Kehler DS, Theou O. The impact of physical activity and sedentary behaviors on frailty levels. Mech Ageing Dev. 2019 Jun;180:29-41.

doi: 10.1016/j.mad.2019.03.004. Epub 2019 Mar 26. PMID: 30926562.

54. Kayihan G. Relationship between daily physical activity level and low back pain in young, female desk-job workers. Int $\mathbf{J}$ Occup Med Environ Health. 2014 Oct;27(5):863-70. doi: 10.2478/s13382-0140315-3. Epub 2014 Sep 24. PMID: 25261333.

55. Kumar S, Negi MP, Sharma VP, Shukla R, Dev R, Mishra UK. Efficacy of two multimodal treatments on physical strength of occupationally subgrouped male with low back pain. J Back MusculoskeletRehabil. 2009;22(3):179-88. doi: 10.3233/BMR2009-0234. PMID: 20023348.

56. Bontrup C, Taylor WR, Fliesser M, Visscher R, Green T, Wippert PM, Zemp R. Low back pain and its relationship with sitting behaviour among sedentary office workers. Appl Ergon. 2019 Nov;81:102894. doi: 10.1016/j.apergo.2019.102894. Epub 2019 Jul 15. PMID: 31422243.

57. Belavy D.L., Miokovic T., Armbrec Richardson C.A., Rittweger J., Felsenb Differential atrophy of the lower-limb mus during prolonged bed-rest, European Jou Applied Physiology, 2009, 107: 489-499.

58. Booth F.W., Weeden S.H., Tseng B.S., E aging on human skeletal muscle and motor $\mathrm{f}$ Medicine \& Science in Sports \& Exercise, 1 556-560.

59. MacDougall J.D., Elder G.C.B., Sale D.G., Moroz J.R., Sutton J.R., Effects of strength training and immobilization on human muscle fibers, European Journal of Applied Physiology, 1980, 43: 25-34.

60. Berg H.E., Eiken O., Miklavcic L., Mekja Hip, thigh and calf muscle atrophy and bo after 5-week bedrest inactivity, European Jo Applied Physiology, 2007, 99: 283-289.

61. U.S. Department of Health and Human Services. 2008 physical activity guidelines for Americans. Be active, healthy, and happy. Washington: USDHHS; 2008.

62. Hoogendoorn WE, van Poppel MN, Bongers PM, Koes BW, Bouter LM. Physical load during work and leisure time as risk factors for back pain. Scand J Work Environ Health. 1999;25(5):387-403, http://dx.doi.org/10.5271/sjweh.451

63. Hoogendoorn $\mathrm{W}$, Bongers $\mathrm{P}$, de Vet $\mathrm{H}$, Ariens G, van Mechelen W, Bouter L. High physical work load and low job satisfaction increase the risk of sickness absence due to low back pain: Results of a prospective cohort study. Occup Environ Med. 2002;59(5):323-8, http://dx.doi.org/ 10.1136/oem.59.5.323.

64. Kopec JA, Sayre EC, Esdaile JM. Predictors of back pain in a general population cohort Spine. 2004;29(1):70-7, http://dx.doi.org/10.1097/01.BRS.00001039 42.81227.7F.

65. Burdorf A, Naaktgeboren B, de Groot HC. Occupational risk factors for low back pain among sedentary workers. J Occup Med. 1993;35(12):1213-20.

How to cite this article: Rambhia T, Bhagra S. Comparison of back-leg muscle strength in physically active and inactive administrative job workers: a cross-sectional study. International Journal of Science \& Healthcare Research. 2021; 6(2): 338-350. DOI: https://doi.org/10. 52403/ijshr.20210460 